\title{
O ESTUPRO GENOCIDA: UMA ABORDAGEM ACERCA DA CONSTITUIÇÃO DO ESTUPRO COMO CRIME INTERNACIONAL DE GENOCÍDIO
}

\author{
Patrick Juliano Casagrande Trindade ${ }^{*}$ \\ Poliana Cristina Gonçalves*
}

\begin{abstract}
RESUMO
A prática do estupro contra as mulheres nos conflitos armados sempre foi tratado como uma estratégia de guerra, razão pela qual este artigo visa analisar o estupro como forma de cometimento do crime de genocídio, demonstrando que a sua prática pode preencher os elementos constitutivos deste crime quando perpetrados com a intenção de destruição, no todo ou em parte, de grupos nacionais, étnicos, raciais e religiosos. Utilizou-se do método indutivo, partindo da análise do estupro como ofensa ao indivíduo para ofensa ao grupo, que tem sua existência transgredida por esta prática violenta.
\end{abstract}

PALAVRAS-CHAVE: Estupro; Conflitos Armados; Genocídio; Direito Internacional; Grupos.

\section{RAPE AS A FORM OF GENOCIDE: AN APPROACH TO THE CONSTITUTION OF RAPE AS AN INTERNATIONAL CRIME OF GENOCIDE}

\begin{abstract}
The practice of the rape against women in armed conflicts has always been treated as a strategy of war, which is why this article aims to analyze the rape as a way of committing the genocide, demonstrating that its practice can fill the constituent elements of this crime when perpetrated with the intention of destroying, in whole or in part, national, ethnic, racial and religious groups. It was used an inductive method, starting from the analysis of rape as an offense to the individual to offense to the group, which has its existence transgressed by this violent practice.
\end{abstract}

KEYWORDS: Rape; Armed Conflicts; Genocide; International right; Groups

\section{INTRODUÇÃO}

\footnotetext{
* Mestre em Direitos Fundamentais pela Universidade de Itaúna/MG. Pós-graduado em Direito Social. Professor titular na Fundação Educacional de Oliveira/MG. Professor titular na Faculdade de Direito de Contagem/MG. Membro da Comissão de Assuntos Carcerários da Ordem dos Advogados do Brasil, subseção Minas Gerais. Graduado em Direito pela Universidade de Itaúna/MG. Advogado. Endereço postal: Rua Uberaba, 195, barro Preto, CEP 30.180-080. Endereço eletrônico: patrick.casagrande@ hotmail.com

* Mestre em Direitos Fundamentais pela Universidade de Itaúna/MG. Pós-graduada em Direito Processual pela UNISUL, Gestão Pública Municipal pela UFU e Gestão Empresarial pelo UNIPAM. Professora não-titular no Centro Universitário de Patos de Minas/MG (UNIPAM). Graduada em Direito pelo Centro Universitário de Patos de Minas/MG. Advogada. Endereço postal: Rua Olegário Maciel n. 1114, bairro Várzea, Patos de Minas/MG. Endereço eletrônico: polianagoncalves.adv@gmail.com
} 
Este artigo visa apresentar as implicações que o crime de estupro cometido em tempos de conflitos armados podem ensejar num determinado grupo, bem como as suas consequências irreparáveis dentro deste contexto.

Das várias formas de eliminação dos grupos nacionais, étnicos, raciais ou religiosos, o estupro nos conflitos armados vem se tornando uma prática sistemática de estratégia de guerra, na medida em que a prática de um ato sexual, quando forçado, constitui-se em ferramenta para humilhar, torturar, ameaçar, desestabilizar o próprio inimigo, ameaçar, sendo que tal crime é passível de ser utilizado como instrumento para genocídio e limpeza étnica.

A relação entre o estupro e o genocídio fica evidente quando o seu uso bélico é realizado com a intenção de destruição dos grupos protegidos, demonstrando que a prática do estupro atende as normas existentes de direito internacional que descrevem as condutas genocidas.

No primeiro capítulo buscou-se tratar da definição do crime de genocídio perante o direito internacional, colacionando os elementos constitutivos do delito em questão, para melhor adequação do estupro como forma de cometê-lo.

No segundo capítulo, a pesquisa trouxe uma abordagem acerca de como o crime de estupro é tratado perante as normas internacionais e como tal crime ofende os direitos humanos em tempos de conflitos.

No terceiro capítulo, o presente artigo apontou, segundo a literatura utilizada, o primeiro caso julgado por um tribunal internacional onde se reconheceu a prática de atos de violência sexual como forma de cometimento de genocídio, tornando-se um marco na história do direito internacional.

Por fim, no quarto capítulo, analisar-se-á como a prática de atos de violência sexual em tempo de guerra podem acarretar na destruição, no todo ou em parte, de grupos ali envolvidos, adequando-se à definição de genocídio segundo sua definição pelas normas internacionais.

A pesquisa utilizada foi a bibliográfica, desenvolvida a partir da análise de artigos científicos, livros e da legislação e documentos internacionais vigentes sobre a violência sexual contra as mulheres, na qual se buscou entender a prática do estupro como artifício para combater os inimigos em situação de guerra e eliminação dos grupos vencidos.

O método utilizado foi o indutivo, partindo de uma abordagem microanalítica do estupro na esfera individual para uma análise geral, buscando demonstrar que o uso bélico do 
estupro atende aos requisitos subjetivos e objetivos do crime de genocídio, notadamente quando se objetiva a eliminação de grupos.

Portanto, este artigo visa analisar a prática o estupro como estratégia de guerra e a sua discussão no cenário internacional.

\section{O CRIME DE GENOCÍDIO E SUA DEFINIÇÃO JURÍDICA}

Do grego genos (raça ou tribo) com o sufixo de origem latina cídio, derivado do vocábulo latino caedere (matar), surge o termo genocídio com base na busca à destruição das bases fundamentais da vida de um grupo, objetivando justamente a destruição deste grupo (LIPPI, 2014).

Somente em 1946, através da Resolução 96-I, foi adotado pela primeira vez o termo genocídio, fundamentado pelas atrocidades cometidas pelos nazistas durante a Segunda Guerra Mundial, mas não direcionado somente a elas (PEREIRA JÚNIOR, 2010).

Esta resolução afirmava que o genocídio é a negação do direito à existência de grupos humanos inteiros. Ademais, considerava que ele constitui um crime sob o manto do Direito Internacional, solicitando, nesta mesma resolução, que o Conselho Econômico e Social das Nações Unidas promovesse estudos necessários a fim de começar a esboçar uma convenção sobre esse crime (UNITED NATIONS, 1946, p. 188-189).

Assessorado por um grupo de especialistas, o Conselho Econômico e Social das Nações Unidas iniciou o projeto de uma convenção com a preocupação central de evitar a confusão do crime de genocídio com os crimes contra a humanidade, uma vez serem distintos (SCHABAS, 2007-2008).

Enviado para o Comitê sobre o Progressivo Desenvolvimento do Direito Internacional e sua Implementação para seus comentários, este órgão declinou esta tarefa de apresentar seus comentários para os Estados-membros, tendo pouca participação, o que fez com que o Comitê remetesse este tema à Assembleia Geral da ONU (LIPPI, 2014).

Superada a fase de debates, em 1948, foi adotada a Convenção sobre o Genocídio pela Assembleia Geral das Nações Unidas, ficando definida a autonomia e definição desta categoria jurídica de crime, passando a possuir a característica de uma infração penal de Direito Internacional (LIMA, 2006). 
A conclusão de que o genocídio precisa ser enfrentado, seja em contexto de paz ou de guerra, transpareceu no artigo $1^{\circ}$ da Convenção para a Prevenção e Repressão do crime de Genocídio: “As Partes Contratantes confirmam que o genocídio, seja cometido em tempo de paz ou em tempo de guerra, é um crime do direito dos povos, que desde já se comprometem a prevenir e a punir." (BRASIL, 1952).

Verificou-se, com isso, a autonomia da definição do crime de genocídio perante o direito internacional, passando a ser infração autônoma de competência dos tribunais internacionais.

Esta definição, diante da sua imprecisão, ficou a cargo da doutrina e jurisprudência, passando por vários conceitos e definições, justamente para trazer a sua adequação típica ao caso concreto, bem como respeitar os princípios norteadores do direito penal, dentre outros o próprio princípio da legalidade.

É definido por Renata Mantovani de Lima (2006, p. 108-109):

De acordo com a Convenção destinada ao genocídio, pode-se defini-lo como um ato de cometer qualquer uma das seguintes infrações: assassinato ou dano grave à integridade física e mental de membros de um grupo; submissão do grupo a condições de existência que acarretem sua destruição física; adoção de medidas capazes de impedir a perpetuação do grupo; ou transferência forçada de crianças de um grupo para outro diferente, desde que sejam realizados com a intenção de destruir, total ou parcialmente, grupos nacionais, étnicos, raciais e religiosos

Trata-se, assim, de uma infração em que a vítima não é atingida em função de características ou qualidades individuais, mas unicamente por ser membro de um grupo (LIMA, 2006).

A presença dos elementos objetivos do tipo, definidos e descritos no artigo $2^{\circ}$, parágrafo $2^{\circ}$ do Estatuto do Tribunal Penal Internacional de Ruanda ${ }^{1}$, bem como no artigo II, da Convenção de 1948, perfazem a constituição do referido crime.

\footnotetext{
${ }^{1}$ Artigo $2^{\circ} .(\ldots)$

$\S 2^{\circ}$. Entende-se por genocídio, qualquer um dos atos que a seguir se enumeram, praticados com a intenção de destruir, no todo ou em parte, um grupo nacional, étnico, racial ou religioso, tais como:

a) Homicídio de membros do grupo;

b) Ofensa grave à integridade física ou moral de membros do grupo;

c) Sujeição intencional do grupo a condições de existência suscetíveis de virem a provocar a sua destruição

física, total ou parcial;

d) Imposição de medidas destinadas a impedir nascimentos no seio do grupo;

e) Transferência forçada de crianças de um grupo para outro. (NAÇÕES UNIDAS, 1994)
} 
E mais, os referidos tipos penais vão além da configuração do referido crime apenas pelo seu cometimento, mas também criminalizam a tentativa e a conspiração para cometê-lo, além da cumplicidade e incitação para tanto.

Merece destaque, ainda, trazer o que se entende por grupos mencionados nos referidos diplomas. Embora mencione expressamente a eliminação de grupos nacionais, étnicos, raciais e religiosos, os referidos diplomas quedaram-se inertes em conceituá-los.

Por definição, grupos são sempre socialmente construídos. O grupo protegido não deve ser imaginado pelo agressor e sua existência deve ser objetiva. No entanto, ela não precisa ser comprovada científica ou factualmente, uma vez que o importante é que haja uma percepção compartilhada socialmente de que o grupo exista (METTRAUX, 2005).

Embora com a definição do que seriam os grupos protegidos pelos citados diplomas legais coubesse a doutrina e a jurisprudência, somente com o julgamento do caso Akayesu, o qual será visto adiante, é que a Câmara de Julgamento definiu cada um desses grupos protegidos pela Convenção sobre Genocídio, quando da prolação da sentença condenatória. A sentença aponta que a intenção do legislador foi proteger apenas grupos estáveis, constituídos de forma a se verem como permanentes e cujo pertencimento ocorre por meio do nascimento. Diante dos critérios adotados para se definirem os grupos protegidos por esta Convenção é que a adesão de seus membros raramente seria desafiada por eles mesmos, pois ela seria vista como automática, contínua e, frequentemente, como irremediável. A Câmara de Julgamento, portanto, definiu que grupo nacional é um conjunto de pessoas percebidas compartilhando um vínculo jurídico de cidadania comum, bem como uma reciprocidade de direitos e deveres; o grupo étnico, cujos membros compartilham uma mesma língua ou cultura; o grupo racial compartilha traços físicos, geralmente (mas nem sempre), ligados a uma região geográfica, independentemente de fatores culturais, nacionais, linguísticos ou religiosos; e o grupo religioso compartilha a mesma religião, denominação ou modo de adoração (INTERNATIONAL CRIMINAL TRIBUNAL FOR RWANDA, 1998).

No entanto, ainda que no corpo da lei haja formalmente a proteção do grupo, nada impede que ela se estenda ao indivíduo, pois apenas pode haver destruição do grupo se for destruído o indivíduo que dele faz parte. Essas pessoas apenas se tornam vítimas individuais por seu pertencimento a determinado grupo cujo direito a existir é tutelado pela tipificação do crime de genocídio (LIPPI, 2014). 
O outro requisito que o crime de genocídio deve possuir está ligado ao elemento subjetivo do tipo, isto é, a intenção do agente em cometer as condutas acima.

Já o elemento subjetivo é tratado igualmente no artigo e nos diplomas legais citados acima, estabelecendo que entende-se por genocídio qualquer das práticas acima expostas, desde que cometidos com a intenção de destruir, no todo ou em parte, um grupo nacional, étnico, racial ou religioso (LIPPI, 2014).

Verifica-se que o delito é construído apenas na modalidade dolosa, não se admitindo a modalidade culposa. Este elemento subjetivo do tipo penal exige que haja, na conduta dos agentes, a clara intenção de eliminar grupos, justamente por ser este elemento que distinguirá este crime dos crimes contra a humanidade, dos crimes de guerra e de crimes comuns.

Ou seja, a vítima não sofre a conduta de forma individualizada, mas sim por fazer parte de um grupo, conforme destaca Akhavan (2005, p. 992):

\footnotetext{
o elemento subjetivo do genocídio no caput do artigo 2(2) como característica que distingue aquele crime, especificamente o requisito da intenção (dolo direto) de destruir, no todo ou em parte, um grupo [...] Esse elemento subjetivo se aplica a todos os atos materiais de genocídio enumerados no artigo 2(a)-(e) do Estatuto. Como esses atos - como assassinato e causar graves danos físicos e mentais - não são crimes internacionais por si sós, é a sua intenção específica que distingue o crime de genocídio de um crime ordinário [...] esse elemento subjetivo também distingue a esfera do Direito Penal Internacional do direito doméstico.
}

Portanto, o dolo específico de eliminar grupos, no todo ou em parte, deve ser demonstrado para que não se confunda com outros delitos.

Assim, exige-se que haja a adequação típica, que é a subsunção da conduta do agente à norma, numa perfeita relação de encaixe, para que seja possível tipificar corretamente o crime de genocídio.

\section{O ESTUPRO E O SEU CONTEXTO NO DIREITO INTERNACIONAL}

O estupro, de uma forma geral, é o ato de violência sexual praticado mediante violência ou grave ameaça, constrangendo alguém à realização de atos de libidinagem de maneira forçada.

O estupro, bem como as outras formas de violência sexual, quando cometidos em época de conflitos armados, seja internacional ou não internacional, constituem uma violação ao Direito Internacional Humanitário. 
No entanto, no contexto internacional o crime de estupro demorou a ser tratado pelos diplomas internacionais diante da ideia de inferioridade feminina permeada durante séculos em detrimento a um discurso teórico masculinizado no cenário internacional.

Embora em meados do século XVIII já se sabia da existência de leis de guerra, ainda que baseada em costumes ou em códigos militares domésticos ou até mesmo em normas religiosas, foi apenas no ano de 1863 que os Estados Unidos da América elaboraram a primeira legislação internacional dos costumes de guerra, chamado de Código Lieber, que trouxe a proibição da prática do estupro, listado como um dos crimes de guerra mais grave quando cometido por aqueles em conflitos armados, no entanto, classificado como crime de disciplina da tropa (AZEVEDO, 2014).

Já em 1907, a Convenção de Haia trouxe a proteção das mulheres dispondo que os direitos de família, da vida das pessoas, de honra e da propriedade privada deveriam ser respeitados, sem, contudo, mencionar expressamente a proibição do estupro. Após a Primeira Guerra Mundial, uma comissão instituída verificou que o crime de estupro estava entre os mais praticados durante este período de guerra. Já após a Segunda Guerra Mundial, ainda com evidências da prática deste crime, o Tribunal de Nuremberg também se quedou em silêncio (COMPARATO, 2015).

No ano de 1949, quando realizada a IV Convenção de Genebra referente à proteção de civis em tempos de guerra, houve a aprovação de um artigo que fazia menção expressamente à violação sexual e à prostituição forçada. Após, já com os protocolos adicionais da referida Convenção, dispuseram que a mulher deveria ser objeto de especial respeito e proteção contra o estupro e outras formas de violência sexual em defesa da sua dignidade pessoal e da sua honra (AZEVEDO, 2014).

Apenas no ano de 1993, o Conselho de Direitos Humanos da Organização das Nações Unidas reconhece, pela primeira vez, a prática de estupro como crime de guerra. Ainda no mesmo ano, o Tribunal Penal Internacional para a Iugoslávia considera o estupro como crime contra a humanidade em suas sentenças condenatórias. De igual forma, em 1994, o Tribunal Penal Internacional para Ruanda não só declara a prática do estupro durante os conflitos armados como delito contra a humanidade, mas também o considera como ato de genocídio (COMPARATO, 2015).

Em 1998, quando da aprovação do Estatuto de Roma e a criação do Tribunal Penal Internacional, este estabeleceu, em seu artigo $7^{\circ}$, a tipificação do crime de estupro e outros 
atos de violência sexual como crimes contra a humanidade e, neste mesmo sentido, estabeleceu, em seu artigo $8^{\circ}$, que estas práticas são consideradas como crimes de guerra (BRASIL, 2002).

Assim expressa o artigo $7^{\circ}$ do referido Estatuto (BRASIL, 2002):

Para os efeitos do presente Estatuto, entende-se por "crime contra a humanidade", qualquer um dos atos seguintes, quando cometido no quadro de um ataque, generalizado ou sistemático, contra qualquer população civil, havendo conhecimento desse ataque:

(...)

g) Agressão sexual, escravatura sexual, prostituição forçada, gravidez forçada, esterilização forçada ou qualquer outra forma de violência no campo sexual de gravidade comparável; (...)

O mencionado estatuto demonstrou seu caráter inovador, dando atenção especial ao s crimes sexuais, inclusive exigindo em sua composição juízes especializados em determinadas matérias, como a violência contra as mulheres e crianças, conforme dispõe seu artigo 36.

Ocorre que, embora tratado pelos diplomas internacionais, fica evidente a ausência de uma norma cogente que possa definir o crime de estupro dentro dos instrumentos de direito internacional, uma vez que sua definição não está listada em nenhum tratado internacional de forma específica.

O que se verifica é que a violência, como forma de praticar os delitos internacionais, é trazida em vários crimes definidos nos tratados. Porém, ainda que o estupro seja trazido nestes mesmos delitos e diplomas, não está designado como delito autônomo trazido por estes instrumentos internacionais, mas apenas como forma de cometimento.

Verifica-se, através dos instrumentos internacionais existentes, a preocupação com a proteção à mulher, de embasamento social, conforme explicita a Convenção sobre a eliminação de todas as formas de discriminação contra a mulher, em seu artigo $3^{\circ}$ :

Os Estados-Partes tomarão, em todas as esferas e, em particular, nas esferas política, social, econômica e cultural, todas as medidas apropriadas, inclusive de caráter legislativo, para assegurar o pleno desenvolvimento e progresso da mulher, com o objetivo de garantir-lhe o exercício e gozo dos direitos humanos e liberdades fundamentais em igualdade de condições com o homem. (BRASIL, 2002)

Isto leva a conclusão de que o delito de estupro não está voltado diretamente aos atos de violência sexual, mas especialmente voltado aos aspectos sociais de proteção à mulher diante do direito internacional. 
Inclusive, os instrumentos internacionais que inauguram o crime de estupro estão ligados ao direito à honra que caracteriza todo e qualquer ser humano e a violência sexual é tida como um crime que ofende este bem jurídico, levando-se em consideração o respeito à pessoa.

Assim, o estupro é considerado como uma ofensa à integridade física, mental e moral das vítimas, devendo ser punido pelos órgãos internacionais sob a ótica do direito internacional.

\section{O CASO AKAYESU E O RECONHECIMENTO DO ESTUPRO GENOCIDA}

O caso em análise é apontado pela literatura como a primeira condenação onde se reconhecera o estupro como forma de constituição do crime de genocídio realizado nos conflitos armados em Ruanda, além de trazer parâmetros para a definição do estupro em âmbito internacional.

O julgamento se deu em 1997, perante a Câmara de Julgamentos do Tribunal Penal Internacional de Ruanda, presidida pelo juiz Laïty Kama e composta pelos juízes Lennart Aspegren e a juíza Navanethem Pillay (INTERNATIONAL CRIMINAL TRIBUNAL FOR RWANDA, 1998).

Quando ocorreu o genocídio em Ruanda em 1994, o país era dividido em vários municípios, cada um governado por um prefeito. Esses municípios eram divididos em pequenas comunidades que ficavam sob a autoridade de um responsável denominado bourgmestre ${ }^{2}$.

Jean Paul Akayesu foi, assim, o responsável por exercer funções executivas e manter a ordem pública em Taba, uma dessas pequenas comunidades, de abril de 1993 até junho de 1994, estando sujeito à autoridade do prefeito. Ele detinha o controle da polícia central e das polícias das regiões rurais ruandesas, bem como era o responsável pela administração da justiça e execução das leis, sempre sujeito à autoridade do prefeito.

O Tribunal Penal Internacional de Ruanda, inicialmente, não o acusou por crimes relativos aos crimes sexuais. Ocorre que, numa das sessões deste julgamento, uma testemunha, denominada como "testemunha J", relatou sobre os crimes de estupros

\footnotetext{
${ }^{2}$ Bourgmestre é a autoridade local de uma determinada comunidade ruandesa, estando sujeito apenas ao prefeito.
} 
presenciados, especialmente o crime de estupro realizado em face da sua filha, todos praticados por membros do interahamwe $\mathrm{e}^{3}$.

Segundo o relatório (INTERNATIONAL CRIMINAL TRIBUNAL FOR RWANDA, 1998, p. 169):

\begin{abstract}
Alegações de violência sexual vieram à atenção da Câmara pela primeira vez através dos relatos da testemunha $\mathbf{J}$, uma mulher Tutsi que disse que sua filha de seis anos de idade foi estuprada por três membros da Interahamwe quando eles foram matar o pai dela. Em juízo, a testemunha J também afirmou que ela ouviu falar que meninas estavam sendo estupradas no bureau commune.
\end{abstract}

Além desta testemunha acima, outras também relataram a ocorrência de vários estupros, salientando, inclusive, que Jean Paul Akayesu estava presente quando os referidos estupros ocorriam.

Com essas novas informações, a acusação requisitou uma audiência perante a Câmara de Julgamento e fez uma moção oral, pedindo para emendar o Indictment ${ }^{4}$, considerando os testemunhos que afirmaram a ocorrência de crimes sexuais durante o genocídio.

Ao analisar as provas colhidas em relação à violência sexual, a Câmara de Julgamento considerou que Akayesu não só sabia das violações sexuais ocorridas nas comunidades onde era o responsável, como não houve nenhuma prova de que ele não tinha como prevenir os estupros ou até mesmo de punir os agressores. Pelo contrário, as provas colhidas e submetidas ao crivo do Tribunal demonstrou que Akaeysu ordenou, instigou, contribuiu e incentivou as práticas da violência sexual em Taba (INTERNATIONAL CRIMINAL TRIBUNAL FOR RWANDA, 1998).

Diante de todas as provas apresentadas, a Câmara de Julgamento condenou Akayesu, onde o Tribunal, onde se adotou uma definição de estupro no Direito Internacional como sendo "uma invasão física de natureza sexual, que inclui estupro, como qualquer ato de natureza que é cometido sobre uma pessoa, sob circunstâncias que são coercitivas" (INTERNATIONAL CRIMINAL TRIBUNAL FOR RWANDA, 1998, p. 275; ASKIN, 1999, p. 319).

E ainda, sobre a violência sexual assim se manifestou o Tribunal (1998, p. 275):

\footnotetext{
${ }^{3}$ A Interahamwe é uma milícia extremista hutu.

${ }^{4}$ Indictment é a peça acusatória dos Tribunais Penais Internacionais.
} 
O Tribunal considera violência sexual, que inclui estupro, como qualquer ato de natureza sexual que é cometido sobre uma pessoa, sob circunstâncias que são coercitivas. A violência sexual não é limitada apenas a uma invasão física do corpo humano, e pode incluir atos que não envolvem penetração, e sequer contato físico.

Ficou evidente que o Tribunal considerou todo ato sexual, com dano à vítima, como violência sexual, sequer permitindo-se discutir se houve consenso ou não, já que as condições eram coercitivas, uma vez que eram realizadas por ameaças, intimidações, opressões mentais e físicas ou quaisquer meios que pudessem diminuir a capacidade de resistência das vítimas.

E mais, complementa o Tribunal, que além da presença dos elementos objetivos necessários para caracterizar o genocídio, havia a presença do elemento subjetivo de exterminar o grupo, já que, em quase todos os atos de estupro contra as mulheres tutsis, havia ainda a intenção de matá-las.

Em outro trecho da sentença condenatória, o Tribunal decidiu que os atos de violência sexual se constituem genocídio quando cometidos com a intenção de destruir um grupo em particular:

Em relação [...] a [...] estupro e violência sexual, a Câmara deseja sublinhar [...] que, em sua opinião, esses atos constituem genocídio da mesma forma que qualquer outro ato, desde que sejam cometidos com a intenção de destruir, no todo ou em parte, um grupo em particular, alvejado enquanto tal [...] o estupro e a violência sexual [...] constituem danos corporais e mentais graves às vítimas e são, ainda, segundo a Câmara, uma das piores formas de infligir danos à vítima [...] a Câmara está convencida de que os atos de estupro e violência sexual descritos acima foram cometidos somente contra as mulheres tutsis, muitas das quais foram submetidas à pior humilhação pública, mutiladas, e estupradas várias vezes, freqüentemente em público, nas instalações do Bureau Communal ou em outros locais públicos, e muitas vezes por mais de um estuprador. Esses estupros resultaram na destruição física e psicológica das mulheres tutsi, de suas famílias e de suas comunidades. A violência sexual era parte integrante do processo de destruição, especificamente dirigido às mulheres tutsis [...], contribuindo para a sua destruição e à destruição do grupo tutsi como um todo. 732. O estupro de mulheres tutsi era sistemático [...]. Como parte da campanha de propaganda voltada para mobilizar os hutus contra os tutsis, as mulheres tutsis foram apresentadas como objetos sexuais. [...] à Câmara foi dito [...] que, antes de ser estuprada e morta, Alexia [...], Ntereye, e suas duas sobrinhas foram forçadas pela Interahamwe a se despirem, e foram ordenadas a correr e a fazer exercícios "a fim de mostrar as coxas das mulheres tutsi”. O membro da Interahamwe que estuprou Alexia disse, quando ele a jogou no chão e ficou em cima dela, "Vamos agora ver qual como é a vagina de uma mulher tutsi" [...] Akayesu, falando com esse membro da Interahamwe que estava cometendo os estupros, disse-lhe: "Nunca me pergunte de novo como é a vagina de uma mulher tutsi”. Esta representação sexualizada da identidade étnica ilustra graficamente que as mulheres tutsis foram sujeitas à violência sexual porque elas eram tutsis. A violência sexual foi um passo no processo de destruição do grupo tutsi - destruição do espírito, da vontade de viver e da própria vida. (INTERNATIONAL CRIMINAL TRIBUNAL FOR RWANDA, 1998, p. 288). 
Portanto, o Tribunal considerou que não só o estupro, mas também os atos que causam violência sexual constituem crime de genocídio, uma vez que a violência sexual constitui um ato cometido com a intenção de causar graves danos físicos ou mentais aos membros do grupo.

E ainda, reforçou a ideia de que havia um componente étnico, pois os estupros eram cometidos somente contra mulheres tutsi.

Prossegue a Câmara de Julgamento, no parágrafo 733 do julgado, afirmando que:

[...] a Câmara considera que na maioria dos casos, os estupros de mulheres Tutsi em Taba foram acompanhados da intenção de matar essas mulheres. Muitos estupros foram perpetrados perto de valas comuns, para onde as mulheres eram levadas para serem mortas. (INTERNATIONAL CRIMINAL TRIBUNAL FOR RWANDA, 1998, p. 29).

No entanto, a decisão recebeu críticas da comunidade internacional uma vez que o estupro genocida só foi reconhecido pela intenção de matar determinado grupo étnico através da violência sexual cometida na esfera coletiva e não por ser um crime manifestado através de dominação masculina praticado na esfera privada (LIPPI, 2014).

Em contrapartida, há posicionamentos que consideraram a referida decisão um avanço no campo do direito internacional quanto à proteção aos direitos das mulheres. A prática do crime de estupro ocasiona enormes danos físicos e mentais na mulher, demonstrando a relação destes atos de violência sexual à eliminação de grupos, demonstrando a conexão entre esta prática e o crime de genocídio, ultrapassando a mera esfera individual do bem a ser protegido (LIPPI, 2014).

Portanto, esta decisão foi importante no cenário internacional uma vez que possibilitou o reconhecimento do crime de estupro tanto como crime contra a humanidade, quanto como crime de guerra, e ficou ainda consignado que as várias formas de violência sexual perpetradas serviram de instrumentos para o genocídio do povo tutsi, fazendo parte de uma ataque generalizado e sistemático, com o objetivo de destruir física e mentalmente aquele grupo (LIPPI, 2014), sendo certo que o Tribunal para Ruanda, representa um precedente histórico no reconhecimento do crime de estupro qualificado como crime de genocídio, ou seja, a primeira vez que assim é visto por um Tribunal Internacional.

\section{A PRÁTICA DO ESTUPRO COMO FORMA DE GENOCÍDIO NOS CONFLITOS}

\section{ARMADOS}

Revista Brasileira de Direito Internacional | e-ISSN: 2526-0219 | Goiânia | v. 5 | n. 1 | p. 57 - 74 | Jan/Jun. 2019. 
Conforme demonstrado anteriormente, a lista dos atos genocidas é excessivamente imprecisa, cabendo aos Tribunais a tarefa de interpretá-la e pormenorizar as condutas incriminadoras abertas, ou seja, dispositivos penais que exigem juízo de valor do magistrado devido à existência de lacunas legais (LIMA, 2012).

Demonstrou-se, ainda, que o estupro é uma modalidade delituosa capaz de acarretar numa violação da autonomia sexual do indivíduo, mas também para o coletivo, tendo em vista seu poder destrutivo para com o agredido e para o grupo conquistado nos conflitos armados.

E ainda que no contexto internacional haja a tendência em considerar o crime de estupro como um delito individual contra os direitos humanos, não se pode esvaziar somente a essa interpretação, já que a sua prática acarreta numa violação ao direito à vida de certos grupos humanos.

Por isso, além das violações individuais, há um claro reflexo no grupo atacado, já que pode acarretar na castração dos inimigos masculinos conquistados, afirma as mulheres conquistadas como propriedade dos agentes conquistadores; fortalece a solidariedade masculina na batalha, o que estreita os laços entre os vencedores; desumaniza os inimigos; além do principal aspecto que é a realização de uma limpeza étnica do grupo conquistado. Além disso, o estupro ou a ameaça de estupro pode deslocar os povos na fuga contra a violência sexual, bem como acarreta traumas decorrentes desta violação, como a desestabilização familiar, divórcios, abandono e morte das crianças produtos da concepção oriundas do estupro, além de destruir os alicerces culturais que aquele povo se baseia e se mantém (DE VITO, GILL e SHORT, 2009).

O estupro em tempos de conflitos armados também é visto como forma de controle social para suprimir quaisquer esforços para mobilizar a resistência dos conquistados, já que também se trata de um ato de desmoralização do grupo, já que na maioria das vezes é praticado diante dos seus membros, além de mortas e expostas num claro lembrete de que os conquistados devem obediência aos conquistadores.

Conforme elucida Grayzel (1999), a violência sexual contra a mulher tem um efeito simbólico e real no campo de batalha, uma vez que as consequências psicológicas, sociais, culturais, étnicas e médicas do estupro na guerra são devastadoras.

Explica-se. $\mathrm{O}$ ato de estupro como estratégia de guerra e eliminação de grupos se torna tão eficaz por que, além de tudo já tratado acima, atinge a castidade e a maternidade de 
uma comunidade. Na região dos Balcãs, por exemplo, o nome de família deve seguir o nome do pai, independentemente da religião ou etnia da mulher. Assim, se um indivíduo de outra etnia estupra uma mulher pertencente ao grupo, vindo esta a ter o filho, este fruto da concepção não será considerado como pertencente ao grupo, mas sim considerado pela etnia do estuprador (VILHENA; ZAMORA, 2004). Ou seja, carregar e gerir um filho produto do estupro pode ser considerado como um meio cruel de tortura, servindo se exclusão da família e da comunidade de que pertence, atingindo a estrutura social que está inserida.

Não há como afastar a adequação típica do crime de genocídio quando praticado através de atos de violência sexual, já que na sua própria definição, trazida pelos diplomas internacionais, tais atos acarretam, incontestavelmente, dano grave à integridade física e mental dos membros de um grupo, bem como a adoção de medidas que possam impedir a perpetuação do grupo.

Então, ainda que o foco do crime de genocídio no contexto internacional seja a proteção de grupos humanos inteiros, mesmo que a preocupação seja a preservação da existência dos grupos e não a existência individual, não se pode cegar-se ao preenchimento dos elementos objetivos e subjetivos do delito em questão quando praticados através do estupro.

Isso porque esses crimes violam o indivíduo não por causa do comportamento que ele tenha tomado na esfera individual, mas simplesmente por pertencerem a determinados grupos, seja pela etnia, raça, políticos ou religiosos.

Verifica-se que os objetivos dos diplomas internacionais não são apenas a repressão do crime e punição dos agressores, mas também a sua prevenção. Com isso, é o elemento subjetivo do crime de genocídio que o define e não o aspecto quantitativo (LIMA, 2006).

Não há como dissociar a prática do crime de estupro individual das violações à existência dos grupos humanos afetados, isso porque os atos de genocídio são praticados contra o indivíduo pertencentes aos mencionados grupos, gerando uma proteção à importância e necessidade deste indivíduo como um todo (DE VITO, GILL e SHORT, 2009).

Isso é enfatizado pela própria Declaração Universal dos Direitos Humanos (1948) quando menciona a proteção à família, às minorias, onde há a proteção dos direitos do indivíduo no interior do grupo, demonstrando que a proteção não é limitada apenas aos crimes cometidos contra o grupo como um todo. 
Ou seja, ao tratar a prática do genocídio mediante atos de violência sexual de modo diferente é admitir a ausência de uma sanção proporcional ao bem jurídico afetado por esta prática de guerra.

Portanto, quando esta violação sexual ultrapassa a esfera do individual, passando para a esfera coletiva, na busca de eliminação de grupos, concebe-se claramente a presença do estupro como forma de cometimento do genocídio.

\section{CONCLUSÃO}

O presente artigo demonstrou, ainda que merecedor de discussões, que os atos de violência sexual praticados nos conflitos podem ensejar graves danos físicos e mentais aos membros de determinados grupos, além de ser uma prática que pode evitar a perpetuação de uma comunidade.

Considerar o contrário é admitir que não há a intenção do perpetrador em destruir o grupo étnico, utilizando-se como meio para isso a destruição de sua habilidade de procriar, dos danos físicos causados, da imposição dos grupos vencedores, além de desumanizar os inimigos e causar traumas irreparáveis na estrutura social daquela comunidade.

Não se pretende favorecer a dimensão privada da ofensa à dignidade sexual dos ofendidos em detrimento da dimensão pública de eliminação de um grupo, até mesmo por que, nestes casos, não se consegue dissociar tal prática dos elementos objetivos e subjetivos do crime de genocídio.

Assim, deve-se repensar este conceito, aprofundando de forma mais clara no conceito de estupro em tempos de guerra, para não apenas invocar que se trata de uma mera dominação dos homens sobre as mulheres, mas uma dominação exercida contra as mulheres de uma determinada etnia ou raça, com clara intenção de destruí-la.

Reconsiderar esta prática delituosa em tempos de guerra como forma de cometimento do crime de genocídio é adequar à necessidade de uma melhor reparação dos traumas ocorridos quando desta utilização, bem como legitimar uma sanção considerável ao mal causado nestes grupos protegidos pelos direitos humanos.

Portanto, tais crimes cometidos mediante atos de violência sexual, em tempos de guerra, merecem ser investigados e punidos à luz do direito internacional, para que se possibilite uma maior eficácia no combate a tais modalidades de crimes. 


\section{REFERÊNCIAS}

AKHAVAN, Payam. The crime of genocide in the ICTR jurisprudence. Journal of International Criminal Justice, v. 3, n. 4, p. 989-1006, 2005. Disponível em:

<https://academic.oup.com/jicj/article-abstract/3/4/989/2883161>. Acesso em: 05 jan. 2019.

ASKIN, Kelly D. Sexual violence in decisions and indictmentes oh the Yugoslav and Rwandan Tribunals: Currente Status. The American Journal of International Law, v. 93, n. 1, p. 97-123, Jan. 1999. Disponível em: <https://www.cambridge.org/core/journals/americanjournal-of-international-law/article/div-classtitlesexual-violence-in-decisions-andindictments-of-the-yugoslav-and-rwandan-tribunals-current-statusdiv/ BDFED15BC5695B590AFAB9EEDCA05A06>. Acesso em: 06 jan. 2019.

AZEVEDO, F. R. de. A violência sexual contra a mulher e o Direito Internacional. Revista Eletrônica de Direito Internacional, Belo Horizonte, v. 14, p. 2-50, 2014. Disponível em: $<$ http://www.cedin.com.br/wp-content/uploads/2014/05/A-Viol\%C3\%AAncia-SexualContra-a-Mulher-e-o-Direito-Internacional.pdf> . Acesso em: 12 dez. 2018.

BRASIL. Decreto n. 4.388, de 25 de setembro de 2002. Promulga o Estatuto de Roma do Tribunal Penal Internacional. Diário Oficial da União, Brasília, DF, 25 set. 2002. Disponível em: <http://www2.mre.gov.br/dai/tpi.htm>. Acesso em: 17 dez. 2018.

Decreto n. 4.377, de 13 de setembro de 2002. Promulga a Convenção sobre a Eliminação de Todas as Formas de Discriminação contra a Mulher. Diário Oficial da União, 16 set. 2002. Disponível em: <http://www.planalto.gov.br/ccivil_03/decreto/2002 /D4377.htm>. Acesso em: 03 dez. 2018.

Decreto n. 30.822, de 6 maio de 1952 . Promulga a Convenção para a Prevenção e Repressão do crime de Genocídio. Diário Oficial da União, 09 maio. 1952. Disponível em: <http://www2.camara.leg.br/legin/fed/decret/1950-1959/decreto-30822-6-maio-1952339476-publicacaooriginal-1-pe.html>. Acesso em: 03 dez. 2018.

COMPARATO, F. K. A afirmação histórica dos Direitos Humanos. 10. ed. São Paulo: Saraiva, 2015.

DE VITO, Daniela; GILL, Aisha; SHORT, Damien. A tipificação do estupro como genocídio. Revista Internacional de Direito Humanos, n. 6, vol. 10. São Paulo: junho de 2009. Disponível em: <http://www.scielo.br/scielo.php?script=sci_arttext\&pid=S180664452009000100003>. Acesso em: 17 de dez. 2018.

FINGER, M. de O. $\mathrm{O}$ uso sistemático do estupro em conflitos: um estudo de caso acerca de suas motivações no conflito interno na Guatelama (1960-996). 2013. Monografia (Curso de Relações Internacionais) - Faculdade de Ciências Econômicas, Universidade Federal do Rio Grande do Sul, Porto Alegre, 2013. Disponível em: <https://www.lume.ufrgs.br/bitstream/handle/10183/96710/000917410.pdf?sequence=1>. Acesso em: 12 jan. 2019. 
GRAYZEL, Susan. Women's identities at war: Gender, Motherhood and Politicsin Britain na France during first world war. Chapel Hill: University of Carolina Press, 1999.

INTERNATIONAL CRIMINAL TRIBUNAL FOR RWANDA. The Prosecutor vs. JeanPaul Akayesu. Case n. ICTR-96-4-T. Judgment. 1998. Sentença de 02 de setembro, n. ICTR-96-4. Disponível em: <http://www.unictr.org/Portals/0/Case/English/Akayesu/judgement/akay001.pdf>. Acesso em: 15 dez. 2018.

LIMA, Renata Mantovani de. Tribunais Híbridos e Justiça Internacional Penal. Belo Horizonte: Editora Arraes, 2012.

LIMA, Renata Mantovani de. BRINA, Marina Martins da Costa. O Tribunal Penal Internacional. Belo Horizonte: Editora Del Rey, 2006.

LIPPI, Camila Soares. O estupro enquanto genocídio no Tribunal Penal Internacional: um estudo do caso Akayesu. Espaço Jurídico Journal of Law 15.2 (2014): p. 287-314.

Disponível em: <https://editora.unoesc.edu.br/index.php/espacojuridico/ article/viewFile/3771/3486>. Acesso em: 15 dez. 2018.

MAZZUOLI, Valério de oliveira. Curso de Direitos Humanos. 2 ed.: São Paulo. Editora Método, 2015.

METTRAUX, Guénaël. International Crimes and the Ad Hoc Tribunals. Oxford: Oxford University Press, 2005. Disponível em: <http://www.oupcanada.com/catalog/ 9780199207541.html>. Acesso em: 12 fev. 2019.

ORGANIZAÇÃO DAS NAÇOES UNIDAS. Estatuto do Tribunal Penal Internacional para o Ruanda. 1994. Disponível em <http://gddc.ministeriopublico.pt/sites/default/files/ documentos/ instrumentos/EstatutoTIRuanda_links.pdf>. Acesso em: 22 fev.2019.

Declaração Universal de Direitos Humanos. 1948. Disponível em: < https://nacoesunidas.org/wp-content/uploads/2018/10/DUDH.pdf> Acesso em: 03 abr. 2019.

PEREIRA, Haula Hamad Timeni Freire Pascoal; CAVALCANTI, Sabrinna Correia Medeiros. A prática do estupro contra mulheres como estratégia de guerra sob o viés do Direito Internacional. Revista Tema, vol. 6, n. 24/25, 2015. Disponível em: $<$ http://revistatema.facisa.edu.br/index.php/revistatema/article/view/232>. Acesso em: 12 fev. 2019.

PEREIRA JÚNIOR, Eduardo Araújo. O crime de genocídio segundo os Tribunais ad hoc da ONU para a ex-Iugoslávia e Ruanda: Origens, evolução e correlação com os crimes contra a humanidade e crimes de guerra. Curitiba: Juruá, 2010.

PERES, A. C. S. Campos de estupro e a guerra na Bósnia. Cadernos Pagu, Campinas, n. 37 , p. 117-162, dez. 2011. Disponível em: <http://www.scielo.br/scielo.php?pid=S01043332011000200005\&script=sci_arttext $>$. Acesso em: 18 jan. 2019.

RAMOS, André de Carvalho. Curso de Direitos Humanos. $4^{a}$ ed. São Paulo: Saraiva, 2017. 
SCHABAS, William. Origins of the genocide convention: fron Nuremberg to Paris. Case Western Journal of International Law, n. 40, p. 35-55, 2007-2008. Disponível em:

$<$ https://scholarlycommons.law.case.edu/cgi/viewcontent.cgi?referer=https://www.google.co m.br/\&httpsredir=1\&article=1273\&context=jil $>$. Acesso em: 09 mar. 2019.

UNITED NATIONS. General Assembly Resolutions 95 (I) and 96 (I). 1946. Disponível em: <http://daccess-dds-ny.un.org/doc/RESOLUTION/GEN/NR0/033/47/IMG/

NR003347.pdf?OpenElement>. Acesso em: 15 fev. 2019.

VILHENA, J.; ZAMORA, M. H. Além do ato: os transbordamentos do estupro. Revista Rio de Janeiro, Rio de Janeiro, n. 12, p. 115-129, jan./abr. 2004. Disponível em:

<http://www.forumrio.uerj.br/documentos/revista_12/12_dossie_JuniaVilhena.pdf $>$. Acesso em: 21 dez. 2018. 